\title{
PENGARUH RASIO LIKUIDITAS DAN PROFITABILITAS TERHADAP LABA PERUSAHAAN
}

\author{
Ade Rias Okiana ${ }^{1}$ Rawidjo $^{2}$ \\ ${ }^{1}$ STIE Muhammadiyah Jakarta, riiasade@gmail.com \\ ${ }^{2}$ STIE Muhammadiyah Jakarta, rawidjo_ms@ymail.com
}

\begin{abstract}
ABSTRAK
Tujuan dari penelitian ini adalah untuk mengetahui adakah pengaruh current ratio, profit margin, return on assets terhadap laba perusahaan pada PT. Dharma Satya Nusantara. Jenis data dalam penelitian ini adalah data sekunder yang merupakan data kuantitatif yang berupa angka nominal dari perusahaan yang diteliti yaitu berupa laporan keuangan PT. Dharma Satya Nusantara tahun 2013-2016. Pengujian hipotesis dalam penelitian ini menggunakan regresi linear berganda. Hasil uji $\mathrm{T}$ menunjukkan bahwa Current Ratio dan Profit Margin tidak berpengaruh signifikan terhadap laba, sedangkan Return On Assets berpengaruh secara signifikan terhadap laba. Hasil analisis uji $\mathrm{F}$ dan uji Koefisien Determinan $\left(\mathrm{R}^{2}\right)$ menunjukkan bahwa current ratio, profit margin, return on assets berpengaruh secara signifikan terhadap laba perusahaan.
\end{abstract}

Kata Kunci : Laba, Current Ratio, Profit Margin, Return On Assets.

\begin{abstract}
The purpose of this study is to determine whether there is an influence of current ratio, profit margin, return on assets to company profits at PT. Dharma Satya Nusantara. The type of data in this study is secondary data which is quantitative data in the form of nominal figures from the company studied in the form of financial statements of PT. Dharma Satya Nusantara in 2013-2016. Testing the hypothesis in this study using multiple linear regression. T test results indicate that Current Ratio and Profit Margin have no significant effect on earnings, while Return On Assets significantly influence earnings. The results of the analysis of the $F$ test and the Determinant Coefficient $\left(R^{2}\right)$ test show that the current ratio, profit margin, return on assets significantly influence company profits.
\end{abstract}

Keywords: Profit, current ratio, profit margin, return on assets.

\section{PENDAHULUAN}

Pada umumnya masyarakat bisa menilai dan mengukur keberhasilan suatu perusahaan dari kemampuan kinerja manajemen perusahaan dalam menghasilkan laba, hal ini dapat dilihat dari laporan keuangan yang telah diterbitkan oleh perusahaan. Laporan keuangan perusahaan mengandung informasi. Informasi yang terdapat pada laporan keuangan biasanya digunakan oleh berbagai pihak, baik dari pihak intern (pemilik dan manajemen) maupun dari pihak ekstern (kreditor, pemerintah, dan investor). Perusahaan yang tergabung dalam pasar modal harus mampu meningkatkan nilai perusahaannya karena nilai perusahaan yang tinggi tentu memberikan gambaran yang baik dan peluang return yang besar. Dengan persaingan yang semakin meningkat perusahaan harus mampu bertahan dan bersaing dengan industri lainnya. Dimana pada pasar persaingan usaha yang semakin meningkat, perusahaan harus dapat 


\section{JURNAL AKUNTANSI, Vol. 7, No. 2, November (2018)}

mengelola dan mengendalikan setiap aktivitas dalam usaha agar dapat menghasilkan keuntungan produktivitas yang baik serta mutu atau kualitas yang sesuai dengan kebutuhan. Laporan keuangan merupakan informasi penting bagi calon investor, karena dari laporan keuangan inilah dapat diketahui kinerja dari suatu perusahaan.

Tujuan keseluruhan dari laporan keuangan adalah untuk memberikan informasi yang berguna bagi investor dan kreditor dalam pengambilan keputusan investasi dan kredit (Hery, 2016: 4). Laporan keuangan akan menjadi lebih bermanfaat untuk pengambilan keputusan ekonomi apabila laporan keuangan tersebut dapat digunakan untuk melihat peningkatkan kinerja perusahaan yang akan terjadi di masa yang akan datang. Banyak pihak seperti investor, kreditor, analis sekuritas dan pihak-pihak lain yang membutuhkan laporan keuangan sebagai dasar pengambilan keputusan ekonomi. Keputusan ekonomi yang dibuat memerlukan hasil evaluasi atas kemampuan perusahaan dalam menghasilkan kas, laba, dan kepastian dari hasil evaluasi tersebut. Laba dapat diukur dengan cara mencari selisih antara pendapatan yang diperoleh dengan biaya yang dikeluarkan oleh perusahaan sehingga besar kecilnya laba tergantung pada ketepatan pengukuran pendapatan dan biaya.

Laba atau rugi sering dimanfaatkan sebagai ukuran untuk menilai kemampuan perusahaan atau sebagai dasar ukuran penilaian yang lain, laba yang diperoleh perusahaan dipengaruhi oleh berbagai faktor.

Penelitian yang dilakukan oleh Devi Riana \&Lucia Ari Diyani (2016) menunjukkan bahwa secara parsial hanya rasio aktivitas yaitu pada variabel Total Assets Turnover saja yang berpengaruh dalam memprediksi perubahan laba, sedangkan secara simultan rasio likuiditas, rasiosolvabilitas, rasio profitabilitas, dan rasio aktivitas berpengaruh dalam memprediksi perubahan laba. Penelitian lain dilakukan oleh Nurdin Prasetyo (2020) bahwa secara parsial CR(Current Ratio), DER (Debt to Equity Ratio), GPM(Gross Profit Margin) danTAT (Total Assets Turnover) tidak berpengaruh terhadap laba, sedangkan NPM (Net Profit Margin), berpengaruh terhadap laba pada tingkat signifikansi kurang dari 5\%. Secara simultan/bersama-sama CR(Current Ratio), DER (Debt to Equity Ratio), GPM(Gross Profit Margin), NPM (Net Profit Margin) danTAT (Total Assets Turnover), berpengaruh terhadap laba pada tingkat signifikansi kurang dari 5\%.

Berdasarkan penjelasan diatas, maka peneliti tertarik untuk melakukan penelitian tentang pengaruh rasio likuiditas dan profitabilitas terhadap laba perusahaan dengan menggunakan Current Ratio (CR), Profit Margin (PM) dan Return on Assets (ROA) untuk mengetahui adakah pengaruh terhadap laba perusahaan.

\section{KAJIAN PUSTAKA \\ Laporan Keuangan}

Menurut Hery S.E (2014 : 3), laporan keuangan pada dasarnya hasil dari proses akuntansi yang dapat digunakan sebagai alat untuk mengkomunikasikan data keuangan atau aktivitas perusahaan kepada pihak-pihak yang berkepentingan. Sedangkan menurut Harahap (2016 : 105), laporan keuangan menggambarkan kondisi keuangan dan hasil usaha suatu perusahaan pada saat tertentu atau janka waktu tertentu.

\section{Rasio Keuangan}

Menurut Hery (2016) "Rasio keuangan merupakan suatu perhitungan rasio dengan menggunakan laporan keuangan yang berfungsi sebagai alat ukur dalam menilai kondisi keuangan dan kinerja perusahaan". Rasio keuangan menunjukkan hubungan yang sistematis dalam bentuk perbandingan antara perkiraan-perkiraan (pos) laporan keuangan. Agar hasil perhitungan rasio keuangan dapat diinterprestasikan, perkiraan-perkiraan yang dibandingkan haruslan mengarah pada hubungan ekonomis yang penting. Menurut Harahap (2016 : 297) Rasio Keuangan adalah angka yang di peroleh dari hasil 


\section{JURNAL AKUNTANSI, Vol. 7, No. 2, November (2018)}

perbandingan dari satu pos laporan keuangan dengan pos lainnya yang mempunyai hubungan yang relevan dan signifikan.

\section{Jenis Rasio Keuangan}

Menurut Hery (2016: 142) secara garis besar, ada 5 jenis rasio keuangan yang sering digunakan untuk menilai kondisi keuangan dan kinerja perusahaan, kelima jenis rasio keuangan tersebut adalah:

1. Rasio Likuiditas, terdiri dari:

a. Rasio Lancar (Current Ratio)

b. Rasio Cepat (Quick Ratio)

c. Rasio Kas (Cash Rastio)

2. Rasio profitabilitas (profitability ratio), terdiri dari:

a. Hasil Pengembalian atas Aset (Return on Assets)

b. Profit Margin

c. Hasil Pengembalian atas Ekuitas (Return on Equity)

3. Rasio Solvabilitas, terdiri dari:

a. Rasio Utang terhadap Aset (Debt to Asset Ratio)

b. Rasio Utang terhadap Modal (Debt to Equity Ratio)

c. Rasio Utang Jangka Panjang terhadap Modal (Long Term Debt to Equity Ratio)

4. Rasio aktivitas (activity ratio), terdiri dari:

a. Perputaran Piutang Usaha (Accounts Receivable Turn Over)

b. Perputaran Persediaan (Inventory Turn Over)

c. Perputaran Modal Kerja (Working Capital Turn Over)

5. Rasio Penilaian atau Rasio Ukuran Pasar, terdiri dari:

a. Laba Per Lembar Saham Biasa (Earnings Per Share)

b. Rasio Harga terhadap Laba (Price Earnings Ratio)

c. Imbal Hasil Dividen (Dividend Yield)

\section{Laba}

Menurut Suwardjono (2016 : 10), laba dalam teori akuntansi biasanya lebih menunjuk pada konsep yang oleh FASB disebut dengan laba komprehensif. Laba komprehensif dimaknai sebagai kenaikan aset bersih selain yang berasal dari transaksi dengan pemilik. Menurut Imam Ghozali (2007 : 345) dalam pernyataannya: "Laba akuntansi yang merupakan selisih pengukuran pendapatan dan biaya. Besar kecilnya laba sebagai pengukur kenaikan aktiva sangat tergantung pada ketepatan pengukuran pendapat dan biaya".

\section{Faktor-faktor yang Mempengaruhi Laba Perusahaan}

Laba yang diperoleh perusahaan dipengaruhi oleh berbagai faktor. Termasuk laba bersih yang diperoleh perusahaan, menurut Sofyan S. Harahap (2016:233) faktor-faktor yang mempengaruhi laba adalah:

a. Perubahan dalam prinsip akuntansi

Perubahan yang diterima umum dengan prinsip lain juga diterima umum yang lebih baik, misalnya: sebelumnya menggunakan metode penyusutan Straight Line sekarang Declining Balance, sebelumnya metode Average sekarang metode LIFO.

b. Perubahan dalam taksiran

Merubah taksiran yang ditetapkan setelah taksiran tersebut tidak sesuai dengan yang kita taksir, contohnya: umur mesin di taksir 8 tahun, setelah dipakai 5 tahun diketahui bahwa seharusnya umur mesin tadi umurnya 10 tahun.

c. Perubahan dalam pelaporan entity 


\section{JURNAL AKUNTANSI, Vol. 7, No. 2, November (2018)}

Perubahan yang terjadi sebagai akibat dari perubahan materi yang terjadi dalam Entity yang sebelumnya dilaporkan melalui laporan keuangan. Misalnya: Perubahan pelaporan akuntansi karena adanya perubahan struktur perusahaan.

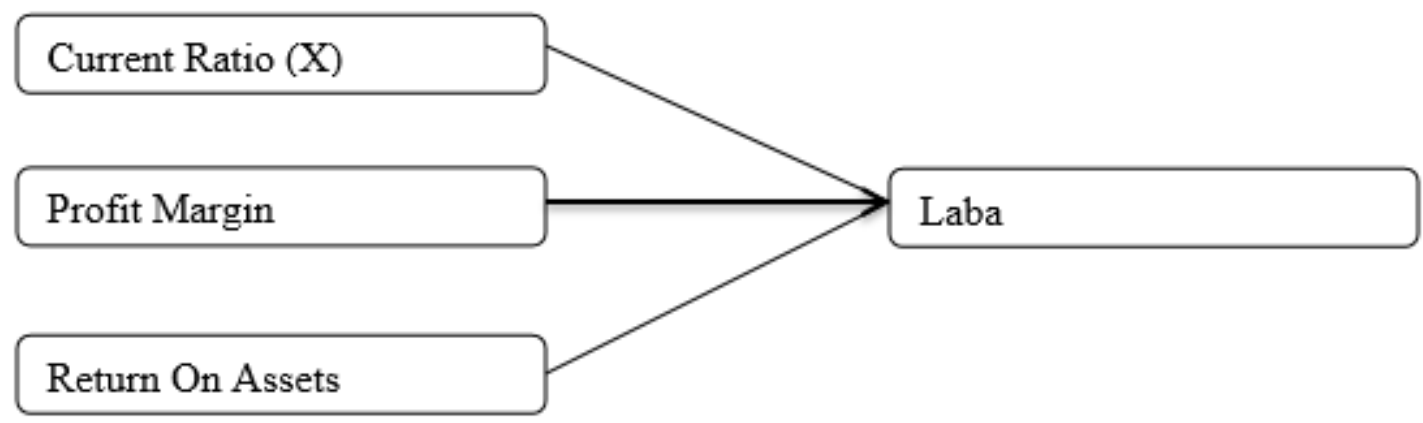

\section{Gambar 1. Kerangka Pikir}

Berdasarkan pada rumusan masalah, hasil penelitian terdahulu, dan kerangka berpikir yang telah diuraikan, maka hipotesis dalam penelitian ini adalah sebagai berikut:

H1 : Terdapat pengaruh yang signifikan antara Current Ratio terhadap laba perusahaan.

$\mathrm{H} 2$ : Terdapat pengaruh yang signifikan antara Profit Margin terhadap laba perusahaan.

H3 : Terdapat pengaruh yang signifikan antara Return On Assets terhadap laba perusahaan.

H4 :Terdapat pengaruh yang signifikan antara Current Ratio, Profit Margin, dan Return On Assets terhadap laba perusahaan.

\section{METODE PENELITIAN}

Objek dari penilitian ini adalah PT Dharma Satya Nusantara Tbk Jakarta. Penelitian ini akan membahas mengenai pengaruh Current Ratio, Profit Margin, Return on Assets dan bagaimana berpengaruhnya terhadap laba perusahaan. Data yang digunakan dalam penelitian ini adalah data sekunder yang diperoleh dari dokumen-dokumen resmi internal perusahaan, studi kepustakaan melalui buku-buku ilmiah dan laporan penelitian, penelitian lapangan dengan mengadakan kunjungan langsung ke Bagian Keuangan (PT Dharma Satya Nusantara), wawancara dan metode observasi. Penulis memperoleh data dari teknik Convenience Sampling.

Teknik yang digunakan adalah analisis regresi linier berganda, yaitu menentukan hubungan antara variabel dependen (Y) dengan variabel independen (X1, X2, X3) dengan bentuk model yang digunakan adalah :

$\mathrm{Y}=\mathrm{a}+\mathrm{b} 1 \mathrm{X} 1+\mathrm{b} 2 \mathrm{X} 2+\mathrm{b} 3 \mathrm{X} 3+\mathrm{e}$

Dimana :

Y $\quad=$ Variabel Dependen

A $=$ konstanta

$\mathrm{b} 1, \mathrm{~b} 2=$ koefisien regresi

$\mathrm{X} 1, \mathrm{X} 2, \mathrm{X} 3=$ Variabel Independen

$\mathrm{E}=$ Error 
Pengujian hipotesis dilakukan dengan membanding tsatistik dengan t-tabel atau dengan membandingkan signifikansi atau p-value (Wati, 2017)

\section{HASIL DAN PEMBAHASAN \\ Deskripsi Data Penelitian}

Data yang digunakan dalam penelitian ini diperoleh dari laporan Laba-Rugi PT. Dhama Satya Nusantara pada tahun 2013-2016. Sedangkan untuk data seperti hutang lancar, aset lancar, total aset dan penjualan diperoleh dari laporan keuangan yang nantinya akan digunakan untuk menganalisa rasio keuangan yang berhubungan dengan rasio likuiditas dan rasio profitabilitas PT. DHARMA SATYA NUSANTARA

Tabel 1.

Laba PT Dharma Satya Nusantara Tbk Periode Juni 2013-Desember 2016

\begin{tabular}{|c|c|lr|}
\hline No. & Triwulan & \multicolumn{2}{|c|}{ Laba } \\
\hline 1 & Jun-13 & $\mathrm{Rp}$ & 114.955 .000 .000 \\
\hline 2 & Sep-13 & $\mathrm{Rp}$ & 123.289 .000 .000 \\
\hline 3 & Des-13 & $\mathrm{Rp}$ & 215.696 .000 .000 \\
\hline 4 & Mar-14 & $\mathrm{Rp}$ & 150.992 .000 .000 \\
\hline 5 & Jun-14 & $\mathrm{Rp}$ & 367.358 .000 .000 \\
\hline 6 & Sep-14 & $\mathrm{Rp}$ & 521.519 .000 .000 \\
\hline 7 & Des-14 & $\mathrm{Rp}$ & 649.794 .000 .000 \\
\hline 8 & Mar-15 & $\mathrm{Rp}$ & 57.922 .000 .000 \\
\hline 9 & Jun-15 & $\mathrm{Rp}$ & 174.403 .000 .000 \\
\hline 10 & Sep-15 & $\mathrm{Rp}$ & 125.790 .000 .000 \\
\hline 11 & Des-15 & $\mathrm{Rp}$ & 314.147 .000 .000 \\
\hline 12 & Mar-16 & $\mathrm{Rp}$ & 20.212 .000 .000 \\
\hline 13 & Jun-16 & $\mathrm{Rp}$ & 28.467 .000 .000 \\
\hline 14 & Sep-16 & $\mathrm{Rp}$ & 24.759 .000 .000 \\
\hline 15 & Des-16 & $\mathrm{Rp}$ & 251.430 .000 .000 \\
\hline
\end{tabular}

Sumber: Laporan Keuangan PT Dharma Satya Nusantara.

Berdasarkan data diatas, maka laba PT. Dharma Satya Nusantara diklasifikasi berdasarkan interval sebagai berikut :

$<50.000 .000 .000$

$=1$

50.000 .000 .000 sampai 99.000 .000 .000

$=2$

100.000.000.000 sampai 149.000.000.000 = 3

150.000.000.000 sampai 199.000.000.000 $=4$

$>200.000 .000 .000$

$=5$

Berdasarkan pada pembagian interval tersebut maka data laba dirubah menjadi:

\begin{tabular}{|c|c|c|}
\hline No. & Triwulan & Laba \\
\hline 1 & Jun-13 & 3 \\
\hline 2 & Sep-13 & 3 \\
\hline 3 & Des-13 & 5 \\
\hline 4 & Mar-14 & 4 \\
\hline 5 & Jun-14 & 5 \\
\hline 6 & Sep-14 & 5 \\
\hline
\end{tabular}




\begin{tabular}{|c|c|c|}
\hline 7 & Des-14 & 5 \\
\hline 8 & Mar-15 & 2 \\
\hline 9 & Jun-15 & 4 \\
\hline 10 & Sep-15 & 3 \\
\hline 11 & Des-15 & 5 \\
\hline 12 & Mar-16 & 1 \\
\hline 13 & Jun-16 & 1 \\
\hline 14 & Sep-16 & 1 \\
\hline 15 & Des-16 & 5 \\
\hline
\end{tabular}

\section{Analisis Rasio}

Rasio Likuiditas

Merupakan rasio yang menggambarkan kemampuan perusahaan dalam memenuhi kewajiban jangka pendeknya yang segera jatuh tempo. Rasio likuiditas menunjukkan kemampuan perusahaan dalam memenuhi kewajiban atau membayar utang jangka pendeknya. Penelitian ini menggnakan Rasio Lancar (Current Ratio)

Tabel 2.

Current Ratio PT Dharma Satya Nusantara Periode Juni 2013 - Des 2016

\begin{tabular}{|c|cc|c|c|}
\hline Triwulan & \multicolumn{2}{|c|}{ Aset Lancar } & Kewajiban Lancar & $\begin{array}{c}\text { Current } \\
\text { Ratio }\end{array}$ \\
\hline Jun-13 & $\mathrm{Rp} 1.863 .821 .000 .000$ & $\mathrm{Rp} 2.008 .517 .000 .000$ & 0,93 \\
\hline Sep-13 & $\mathrm{Rp}$ & 1.921 .078 .000 .000 & $\mathrm{Rp} 2.036 .886 .000 .000$ & 0,94 \\
\hline Des-13 & $\mathrm{Rp} 1.670 .821 .000 .000$ & $\mathrm{Rp} 2.011 .462 .000 .000$ & 0,83 \\
\hline Mar-14 & $\mathrm{Rp} 1.820 .758 .000 .000$ & $\mathrm{Rp} 2.129 .974 .000 .000$ & 0,85 \\
\hline Jun-14 & $\mathrm{Rp} 2.179 .105 .000 .000$ & $\mathrm{Rp} 1.978 .360 .000 .000$ & 1,10 \\
\hline Sep-14 & $\mathrm{Rp} 2.168 .398 .000 .000$ & $\mathrm{Rp} 2.029 .898 .000 .000$ & 1,07 \\
\hline Des-14 & $\mathrm{Rp} 2.402 .841 .000 .000$ & $\mathrm{Rp} 2.113 .192 .000 .000$ & 1,14 \\
\hline Mar-15 & $\mathrm{Rp} 2.435 .501 .000 .000$ & $\mathrm{Rp} 2.294 .837 .000 .000$ & 1,06 \\
\hline Jun-15 & $\mathrm{Rp} 2.190 .841 .000 .000$ & $\mathrm{Rp} 2.040 .693 .000 .000$ & 1,07 \\
\hline Sep-15 & $\mathrm{Rp} 2.155 .333 .000 .000$ & $\mathrm{Rp} 2.040 .814 .000 .000$ & 1,06 \\
\hline Des-15 & $\mathrm{Rp} 2.315 .276 .000 .000$ & $\mathrm{Rp} 2.098 .774 .000 .000$ & 1,10 \\
\hline Mar-16 & $\mathrm{Rp} 2.207 .564 .000 .000$ & $\mathrm{Rp} 2.190 .999 .000 .000$ & 1,01 \\
\hline Jun-16 & $\mathrm{Rp} 2.466 .529 .000 .000$ & $\mathrm{Rp} 2.451 .910 .000 .000$ & 1,01 \\
\hline Sep-16 & $\mathrm{Rp} 2.546 .928 .000 .000$ & $\mathrm{Rp} 2.351 .514 .000 .000$ & 1,08 \\
\hline Des-16 & $\mathrm{Rp}$ & 1.753 .048 .000 .000 & $\mathrm{Rp} 1.961 .618 .000 .000$ & 0,89 \\
\hline
\end{tabular}

Sumber: Laporan Keuangan PT Dharma Satya Nusantara

Rasio ini merupakan perbandingan antara aset lancar dengan kewajiban lancar. Rumus yang digunakan adalah sebagai berikut:

$$
\text { Current Ratio }=\frac{\text { Aset Lacar }}{\text { Utang Lancar }} \times 100 \%
$$




\section{JURNAL AKUNTANSI, Vol. 7, No. 2, November (2018)}

Current Ratio menunjukkan sejauh mana kemampuan aktiva lancar yang dimiliki perusahaan menutupi kewajiban lancar atau hutang yang harus dibayar pada saat jatuh tempo (Kasmir, 2011;130).

\section{Rasio Profitabilitas}

Menurut Hery (2016) rasio profitabilitas merupakan rasio yang menggambarkan kemampuan perusahaan dalam memenuhi seluruh kewajibannya. Apabila semakin baik rasio profitabilitas maka semakin baik menggambarkan kemampuan tingginya perolehan keuntungan perusahaan. Penelitian ini menggunankan Rasio Profit Margin dan Return On Assets

Tabel 3

Profit Margin PT Dharma Satya Nusantara Periode Juni 2013 - Des 2016

\begin{tabular}{|c|c|c|c|c|}
\hline Triwulan & \multicolumn{2}{|r|}{ Laba Bersih } & Kewajiban Lancar & Profit \\
\hline Jun-13 & $\mathrm{Rp}$ & 114.955 .000 .000 & $\mathrm{Rp} \quad 1.700 .301 .000 .000$ & 0,07 \\
\hline Sep-13 & $\mathrm{Rp}$ & 123.289 .000 .000 & $\operatorname{Rp} 2.681 .431 .000 .000$ & 0,05 \\
\hline Des-13 & $\mathrm{Rp}$ & 215.696 .000 .000 & $\mathrm{Rp} \quad 3.842 .182 .000 .000$ & 0,06 \\
\hline Mar-14 & $\mathrm{Rp}$ & 150.992 .000 .000 & $\mathrm{Rp} \quad 1.238 .413 .000 .000$ & 0,12 \\
\hline Jun-14 & $\mathrm{Rp}$ & 367.358 .000 .000 & Rp $\quad 2.564 .269 .000 .000$ & 0,14 \\
\hline Sep-14 & $\mathrm{Rp}$ & 521.519 .000 .000 & $\mathrm{Rp} \quad 3.726 .211 .000 .000$ & 0,14 \\
\hline Des-14 & $\mathrm{Rp}$ & 649.794 .000 .000 & Rp 4.898 .479 .000 .000 & 0,13 \\
\hline Mar-15 & $\mathrm{Rp}$ & 57.922 .000 .000 & $\mathrm{Rp} \quad 1.023 .856 .000 .000$ & 0,06 \\
\hline Jun-15 & $\mathrm{Rp}$ & 174.403 .000 .000 & Rp 2.247 .565 .000 .000 & 0,08 \\
\hline Sep-15 & $\mathrm{Rp}$ & 125.790 .000 .000 & Rp 3.300 .413 .000 .000 & 0,04 \\
\hline Des-15 & $\mathrm{Rp}$ & 314.147 .000 .000 & Rp 4.425 .060 .000 .000 & 0,07 \\
\hline Mar-16 & $\mathrm{Rp}$ & 20.212 .000 .000 & 779.955 .000 .000 & 0,03 \\
\hline Jun-16 & $\mathrm{Rp}$ & 28.467 .000 .000 & $\mathrm{Rp} \quad 1.859 .559 .000 .000$ & 0,02 \\
\hline Sep-16 & $\mathrm{Rp}$ & 24.759 .000 .000 & Rp 2.644 .906 .000 .000 & 0,01 \\
\hline Des-16 & $\mathrm{Rp}$ & 251.430 .000 .000 & Rp 3.942 .024 .000 .000 & 0,06 \\
\hline
\end{tabular}

Sumber: Laporan Keuangan PT Dharma Satya Nusantara

Merupakan rasio yang digunakan untuk mengukur presentase laba bersih atas penjualan bersih.

$$
\text { Profit Margin }=\frac{\text { Laba Bersih }}{\text { Penjualan }} \times 100 \%
$$

Pengertian Profit Marginmenurut Munawir (2010: 89) "Profit margin ini mengukur tingkat keuntungan yang dapat dicapai oleh perusahaan dihubungkan dengan penjualannya". 


\section{JURNAL AKUNTANSI, Vol. 7, No. 2, November (2018)}

Table 4

ROA PT Dharma Satya Nusantara Periode Juni 2013 - Des 2016

\begin{tabular}{|c|cc|cc|c|}
\hline Triwulan & \multicolumn{2}{|c|}{ Laba Bersih } & \multicolumn{2}{c|}{ Kewajiban Lancar } & $\begin{array}{c}\text { Return On } \\
\text { Assets }\end{array}$ \\
\hline Jun-13 & $\mathrm{Rp}$ & 114.955 .000 .000 & $\mathrm{Rp}$ & 5.708 .112 .000 .000 & 0,02 \\
\hline Sep-13 & $\mathrm{Rp}$ & 123.289 .000 .000 & $\mathrm{Rp}$ & 5.901 .570 .000 .000 & 0,02 \\
\hline Des-13 & $\mathrm{Rp}$ & 215.696 .000 .000 & $\mathrm{Rp}$ & 5.921 .055 .000 .000 & 0,04 \\
\hline Mar-14 & $\mathrm{Rp}$ & 150.992 .000 .000 & $\mathrm{Rp}$ & 6.117 .953 .000 .000 & 0,02 \\
\hline Jun-14 & $\mathrm{Rp}$ & 367.358 .000 .000 & $\mathrm{Rp}$ & 6.664 .657 .000 .000 & 0,06 \\
\hline Sep-14 & $\mathrm{Rp}$ & 521.519 .000 .000 & $\mathrm{Rp}$ & 4.608 .570 .000 .000 & 0,11 \\
\hline Des-14 & $\mathrm{Rp}$ & 649.794 .000 .000 & $\mathrm{Rp}$ & 7.174 .488 .000 .000 & 0,09 \\
\hline Mar-15 & $\mathrm{Rp}$ & 57.922 .000 .000 & $\mathrm{Rp}$ & 7.368 .048 .000 .000 & 0,01 \\
\hline Jun-15 & $\mathrm{Rp}$ & 174.403 .000 .000 & $\mathrm{Rp}$ & 7.349 .855 .000 .000 & 0,02 \\
\hline Sep-15 & $\mathrm{Rp}$ & 125.790 .000 .000 & $\mathrm{Rp}$ & 7.454 .278 .000 .000 & 0,02 \\
\hline Des-15 & $\mathrm{Rp}$ & 314.147 .000 .000 & $\mathrm{Rp}$ & 7.853 .275 .000 .000 & 0,04 \\
\hline Mar-16 & $\mathrm{Rp}$ & 20.212 .000 .000 & $\mathrm{Rp}$ & 7.925 .781 .000 .000 & 0,00 \\
\hline Jun-16 & $\mathrm{Rp}$ & 28.467 .000 .000 & $\mathrm{Rp}$ & 8.243 .727 .000 .000 & 0,00 \\
\hline Sep-16 & $\mathrm{Rp}$ & 24.759 .000 .000 & $\mathrm{Rp}$ & 8.402 .573 .000 .000 & 0,00 \\
\hline Des-16 & $\mathrm{Rp}$ & 251.430 .000 .000 & $\mathrm{Rp}$ & 8.183 .318 .000 .000 & 0,03 \\
\hline
\end{tabular}

Sumber: Laporan Keuangan PT Dharma Satya Nusantara

Merupakan rasio yang menunjukkan seberapa besar kontribusi aset dalam menciptakan laba bersih. Dengan kata lain, rasio ini digunakan untuk mengukur seberapa besar jumlah laba bersih yang akan dihasilkan dari setiap dana yang tertanam dalam total aset.

$$
R O A=\frac{\text { Laba Bersih }}{\text { Total Aset }} \times 100 \%
$$

Return On Asset (ROA) menurut Kasmir (2012:201) adalah rasio yang menunjukan hasil (return)atas jumlah aktiva yangdigunakan dalam perusahaan. Selain itu, ROA memberikan ukuran yang lebih baik atas profitabilitas perusahaan karena menunjukan efektivitas manajemen

\section{Pengujian Asumsi Klasik}

Dari ketiga variabel akan dilakukan analisis melalui perhitungan untuk mengetahui pengaruh Current atio (X1), Profit Margin (X2) dan Return On Assets (X3) terhadap laba (Y). Untuk mempermudah perhitungan maka penulis menyajikan data sebagai berikut: 
Table 5

Current Ratio, Profit Margin dan Return On Assets terhadap Laba

\begin{tabular}{|c|c|c|c|cr|}
\hline Triwulan & Current Ratio & Profit Margin & $\begin{array}{c}\text { Return On } \\
\text { Assets }\end{array}$ & \multicolumn{2}{|c|}{ Laba Bersih } \\
\hline Jun-13 & 0,93 & 0,07 & 0,02 & $\mathrm{Rp}$ & 114.955 .000 .000 \\
\hline Sep-13 & 0,94 & 0,05 & 0,02 & $\mathrm{Rp}$ & 123.289 .000 .000 \\
\hline Des-13 & 0,83 & 0,06 & 0,04 & $\mathrm{Rp}$ & 215.696 .000 .000 \\
\hline Mar-14 & 0,85 & 0,12 & 0,02 & $\mathrm{Rp}$ & 150.992 .000 .000 \\
\hline Jun-14 & 1,10 & 0,14 & 0,06 & $\mathrm{Rp}$ & 367.358 .000 .000 \\
\hline Sep-14 & 1,07 & 0,14 & 0,11 & $\mathrm{Rp}$ & 521.519 .000 .000 \\
\hline Des-14 & 1,14 & 0,13 & 0,09 & $\mathrm{Rp}$ & 649.794 .000 .000 \\
\hline Mar-15 & 1,06 & 0,06 & 0,01 & $\mathrm{Rp}$ & 57.922 .000 .000 \\
\hline Jun-15 & 1,07 & 0,08 & 0,02 & $\mathrm{Rp}$ & 174.403 .000 .000 \\
\hline Sep-15 & 1,06 & 0,04 & 0,02 & $\mathrm{Rp}$ & 125.790 .000 .000 \\
\hline Des-15 & 1,10 & 0,07 & 0,04 & $\mathrm{Rp}$ & 314.147 .000 .000 \\
\hline Mar-16 & 1,01 & 0,03 & 0,00 & $\mathrm{Rp}$ & 20.212 .000 .000 \\
\hline Jun-16 & 1,01 & 0,02 & 0,00 & $\mathrm{Rp}$ & 28.467 .000 .000 \\
\hline Sep-16 & 1,08 & 0,01 & 0,00 & $\mathrm{Rp}$ & 24.759 .000 .000 \\
\hline Des-16 & 0,89 & 0,06 & 0,03 & $\mathrm{Rp}$ & 251.430 .000 .000 \\
\hline
\end{tabular}

Sumber: Laporan Keuangan PT Dharma Satya Nusantara

Dari data diatas, maka akan dilakukan analisis data untuk mengetahui pengaruh antara variabel X1, X2, X3 terhadap variabel Y. Analisis data dilakukan dengan beberapa tahap dengan menggunakan SPSS.

\section{Uji Normalitas}

Gambar 2

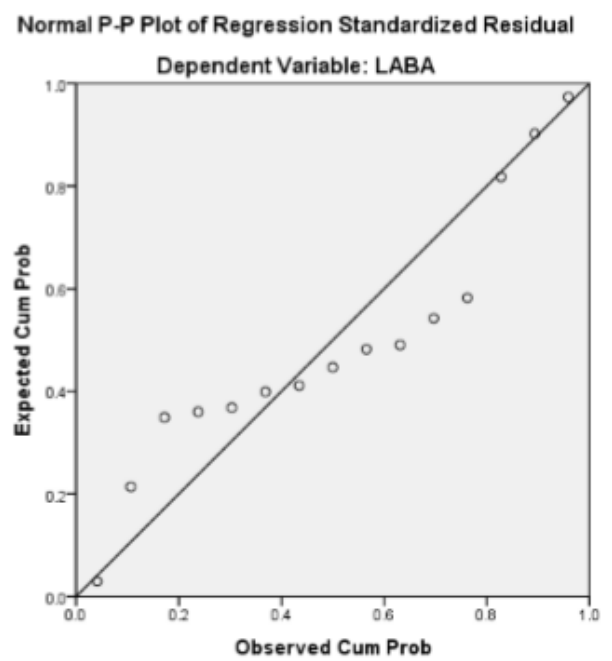




\section{JURNAL AKUNTANSI, Vol. 7, No. 2, November (2018)}

Berdasarkan hasil output SPSS di atas kita dapat melihat grafik plot. Dimana gambar P-Plot terlihat titiktitik mengikuti dan mendekati garis diagonalnya sehingga dapat disimpulkan bahwa model regresi memenuhi asumsi normalitas.

Tabel 6

One-Sample Kolmogorov-Smirnov Test

\begin{tabular}{|ll|r|r|r|r|}
\hline & & \multicolumn{1}{|c|}{ Laba } & Current_Ratio & Profit_Margin & \multicolumn{1}{c|}{ ROA } \\
\hline $\mathrm{N}$ & & 15 & 15 & 15 & 15 \\
Normal Parameters & Mean & 3.4667 & 1.0093 & .0720 & .0320 \\
& Std. Deviation & 1.59762 & .09779 & .04246 & .03234 \\
Most Extreme & Absolute & .231 & .231 & .185 & .245 \\
Differences & Positive & .169 & .110 & .185 & .245 \\
& Negative & -.231 & -.231 & -138 & -.161 \\
Kolmogorov-Smimov Z & & .896 & .895 & .718 & .948 \\
Asy mp. Sig. (2-tailed) & .398 & .399 & .681 & .330 \\
\hline
\end{tabular}

a. Test distribution is Normal.

b. Calculated from data.

Berdasarkan tabel di atas, nilai Absolute laba 0,231. Apabila dibandingkan dengan kolmogorov tabel pada sample $\mathrm{N}=15$ yaitu 0,338 , maka $0,231<0,338$ yang berarti data berdistribusi normal. Hal ini dibuktikan dengan hasil uji probabilitas pada SPSS yaitu lihat pada nilai Asymp. Sig. (2 tailed) nilainya 0,398 dimana $>0,05$ yang artinya data berdistribusi normal.

\section{Uji Multikoliniearitas}

Table 7

Coefficients

\begin{tabular}{|c|c|c|c|c|c|c|c|c|}
\hline \multirow[b]{2}{*}{ Mod } & & \multicolumn{2}{|c|}{$\begin{array}{c}\text { Unstandardized } \\
\text { Coefficients }\end{array}$} & \multirow{2}{*}{$\begin{array}{c}\text { Standardized } \\
\text { Coefficients } \\
\text { Beta } \\
\end{array}$} & \multirow[b]{2}{*}{$t$} & \multirow[b]{2}{*}{ Sig. } & \multicolumn{2}{|c|}{ Collinearity Statistics } \\
\hline & & B & Std Error & & & & Tolerance & VF \\
\hline \multirow[t]{4}{*}{1} & (Constant) & 6.445 & 2.928 & & 2.201 & .050 & & \\
\hline & Current_Ratio & -4.737 & 2.866 & -.290 & -1.653 & .127 & .885 & 1.130 \\
\hline & Profit_Margin & 12.545 & 10.967 & .333 & 1.144 & .277 & .321 & 3.118 \\
\hline & ROA & 28.118 & 14.913 & 569 & 1.885 & .086 & 299 & 3.344 \\
\hline
\end{tabular}

a. Dependent Variable: Laba

Dari tabel di atas menggambarkan bahwa tidak ada problem multikolinieritas. Hal ini dapat dilihat dari nilai Tolerance (TOL) yang lebih besar dari 0,10 dan nilai Variance Inflation Factor (VIF) < 10 yaitu pada:

1. Nilai Tolerance Variabel Current Ratio $(X 1)=0,885>0,10$, Profit Margin $(X 2)=0,321>0,10$, Return On Assets (X3) =0,299>0,10

2. Nilai VIF Variabel Current Ratio $(X 1)=1,130<10$, Profit Margin $(X 2)=3,118<10$, Return On Assets $(\mathrm{X} 3)=3,344<10$

\section{Uji Autokorelasi}




\section{JURNAL AKUNTANSI, Vol. 7, No. 2, November (2018)}

Table 8

Model Summary ${ }^{b}$

\begin{tabular}{|l|r|r|r|r|r|}
\hline Model & \multicolumn{1}{|c|}{ R } & R Square & $\begin{array}{c}\text { Adjusted } \\
\text { R Square }\end{array}$ & $\begin{array}{r}\text { Std. Error of } \\
\text { the Estimate }\end{array}$ & $\begin{array}{c}\text { Durbin- } \\
\text { Watson }\end{array}$ \\
\hline 1 & $.837^{9}$ & .700 & .619 & .98675 & 1.955 \\
\hline
\end{tabular}

a. Predictors: (Constant), ROA, Current_Ratio, Profit_Margin

b. Dependent Variable: Laba

Dari tabel di atas terdapat nilai DW yang di hasilkan dari model regresi adalah 1,955. Dengan tabel DW dengan signifikan 0,05 dan jumlah data $(n)=15$ serta jumlah data $(n)=15$ serta jumlah variabel independen $(\mathrm{K})=3$ di peroleh nilai DL sebesar 0,814 dan DU sebesar 1,750.

Nilai DW 1,955 lebih besar dari DU yaitu 1,750 dan kurang dari (4-DU) $=4-1,750=2,250$ atau 1,955 > $1,750<2,250$ sehingga dapat di simpulkan tidak terdapat autokorelasi.

\section{Uji Heteroskedastisitas}

Uji heteroskedastisitas bertujuan menguji apakah dalam model regresi terjadi ketidaksamaan varian dari residual satu pengamatan ke pengamatan yang lain.

Scatterplot

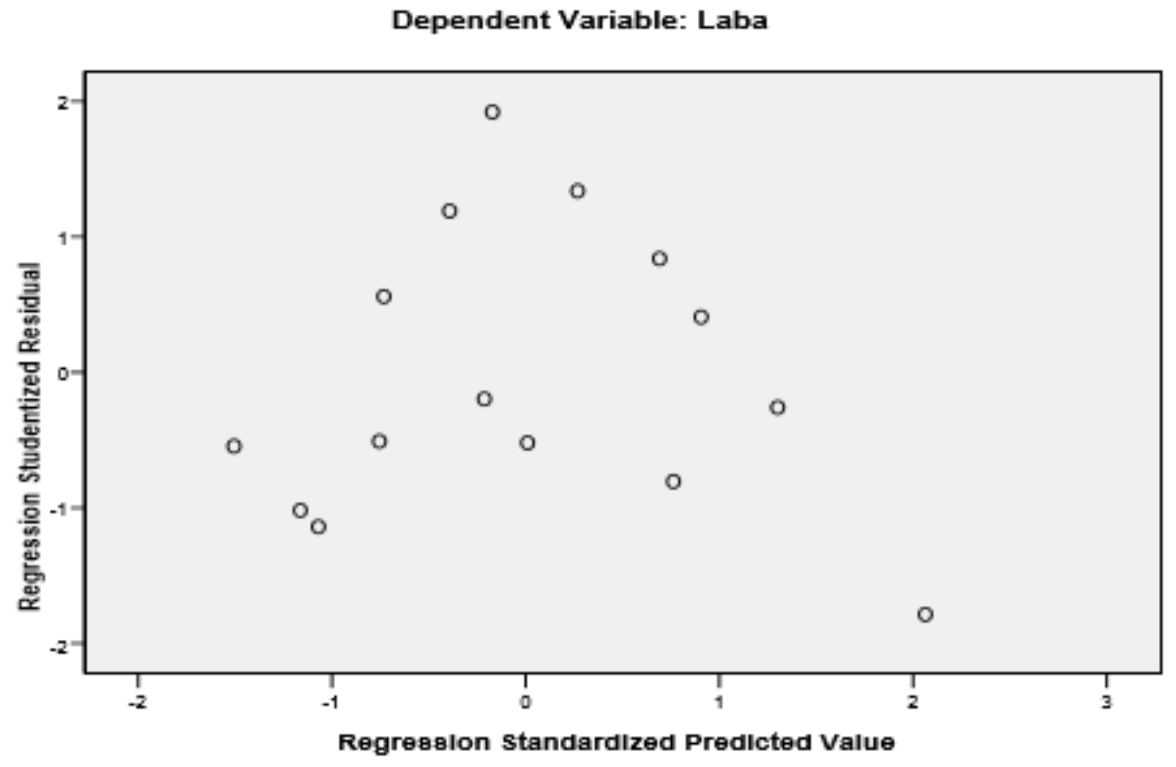

Gambar 3. Uji Heteroskedastisitas

Berdasarkan gambar diatas, dapat diketahui bahwa titik-titik menyebar di sekitar angka 0 dan titik-titik tidak mengumpul. Dapat disimpulkan bahwa tidak terjadi heteroskedastisitas dalam model regresi. 


\section{JURNAL AKUNTANSI, Vol. 7, No. 2, November (2018)}

\section{Uji Validitas}

Tabel 9

Case Processing Summary

\begin{tabular}{|ll|r|r|}
\hline & & $\mathrm{N}$ & \multicolumn{1}{|c|}{$\%$} \\
\hline Cases & Valid & 15 & 100.0 \\
& Excluded & 0 & .0 \\
& Total & 15 & 100.0 \\
\hline
\end{tabular}

a. Listwise deletion based on all variables in the procedure.

Berdasarkan tabel di atas, terdapat 15 data yang semuanya di proses (tidak ada data yang hilang), sehingga tingkat kevalidannya $100 \%$.

\section{Uji Hipotesis}

a. Koefisien Determinan $\left(\mathrm{R}^{2}\right)$

Table 10. Hasil Uji Koefisien Determinan $\left(\mathbf{R}^{2}\right)$

Model Summary ${ }^{b}$

\begin{tabular}{|l|r|r|r|r|r|}
\hline Model & R & R Square & $\begin{array}{c}\text { Adjusted } \\
\text { R Square }\end{array}$ & $\begin{array}{c}\text { Std. Error of } \\
\text { the Estimate }\end{array}$ & $\begin{array}{c}\text { Durbin- } \\
\text { Watson }\end{array}$ \\
\hline 1 & $.837^{\mathrm{a}}$ & .700 & .619 & .98675 & 1.955 \\
\hline
\end{tabular}

a. Predictors: (Constant), ROA, Current_Ratio, Profit_Margin

b. Dependent Variable: Laba

Dari tabel Model Summary diatas menunjukkan Angka R hitung sebesar 0,837. Angka R Square ( $\left.\mathrm{R}^{2}\right)$ atau koefisien determinasi adalah 0,700. Besarnya angka koefisien $70 \%$ menunjukkan bahwa Laba ditentukan oleh Current Ratio, Profit Margin dan ROA sebesar 70\%. Sedangkan sisanya 30\% di pengaruhi oleh faktor lain yang tidak diteliti.

\section{b. Uji F Statistik}

Uji F dilakukan untuk menguji pengaruh antara variabel bebas terhadap variabel terikat secara bersamasama.

\section{Tabel 11}

ANOVA

\begin{tabular}{|ll|r|r|r|r|r|}
\hline \multicolumn{1}{|c|}{} & \multicolumn{1}{c|}{$\begin{array}{c}\text { Sum of } \\
\text { Sodel }\end{array}$} & Squares & df & Mean Square & F & Sig. \\
\hline 1 & Regression & 25.023 & 3 & 8.341 & 8.566 & $.003^{\circ}$ \\
& Residual & 10.711 & 11 & .974 & & \\
& Total & 35.733 & 14 & & & \\
\hline
\end{tabular}

a. Predictors: (Constant), ROA, Current_Ratio, Profit_Margin

b. Dependent Variable: Laba

Dari hasil uji anova atau $\mathrm{F}$ test menunjukkan bahwa $\mathrm{F}$ hitung adalah 8,566 $>$ dari $\mathrm{F}$ tabel $=3,06$ dengan tingkat signifikansi 0,003. Karena 0,003 lebih kecil dari 0,05 maka pengaruh antara variabel independen 


\section{JURNAL AKUNTANSI, Vol. 7, No. 2, November (2018)}

terhadap dependen dinyatakan signifikan. Oleh karena itu, untuk tahun periode 2013-2016 keseluruhan hipotesis menyatakan bahwa variabel independen disini adalah Current Ratio, Profit Margin dan Return On Assets memiliki pengaruh yang signifikan terhadap Laba Perusahaan.

\section{Uji T Statistik}

Uji T digunakan untuk menguji atau mengetahui ada tidaknya hubungan atau pengaruh yang berarti antara variabel bebas secara parsial terhadap variabel terikat.

Hipotesis :

Ho $=$ koefisien regresi tidak signifikan

$\mathrm{H} 1$ = koefisienregresisignifikan

Pengambilan keputusan berdasarkan nilai signifikan :

Jika nilai signifikan $>0.05$, maka Ho diterima

Jika nilai signifikan $<0,05$, maka Ho ditolak

Tabel 12

Coefficients ${ }^{\mathrm{a}}$

\begin{tabular}{|c|c|c|c|c|c|c|c|c|}
\hline \multirow{2}{*}{\multicolumn{2}{|c|}{ Model }} & \multicolumn{2}{|c|}{$\begin{array}{c}\text { Unstandardized } \\
\text { Coefficients }\end{array}$} & \multirow{2}{*}{$\begin{array}{c}\text { Standardized } \\
\text { Coefficients } \\
\text { Beta }\end{array}$} & \multirow[b]{2}{*}{$\mathrm{t}$} & \multirow[b]{2}{*}{ Sig. } & \multicolumn{2}{|c|}{ Colinearity Statistics } \\
\hline & & $\mathrm{B}$ & Std. Error & & & & Tolerance & VF \\
\hline \multirow[t]{4}{*}{1} & (Constant) & 6.445 & 2.928 & & 2.201 & .050 & & \\
\hline & Current_Ratio & -4.737 & 2.866 & -.290 & -1.653 & .127 & .885 & 1.130 \\
\hline & Prof it_Margin & 12.545 & 10.967 & .333 & 1.144 & .277 & .321 & 3.118 \\
\hline & $\mathrm{ROA}$ & 28.118 & 14.913 & .569 & 1.885 & .086 & .299 & 3.344 \\
\hline
\end{tabular}

a. Dependent Variable: Laba

Berdasarkan tabel diatas dapat dijelaskan bahwa hasil uji thitung menunjukkan sebagai berikut : Uji t1 hitung $=1,653<$ dari $\mathrm{t}$ tabel $=1,753$ yang berarti Current Ratio tidak berpengaruh signifikan terhadap Laba.

Uji $\mathrm{t} 2$ hitung $=1,144<$ dari $\mathrm{t}$ tabel $=1,753$ yang berarti Profit Margin tidak berpengaruh signifikan terhadap Laba.

Uji t3 hitung $=1,885>$ dari $\mathrm{t}$ tabel $=1,753$ yang berarti ROA berpengaruh terhadap Laba dengan tingkat signifikansi 0,86 atau > 0,05 yang berarti tidak signifikan, namun berpengaruh signifikan pada level signifikansi $10 \%$.

\section{Analisis Regresi Berganda}

Berdasarkan tabel diatas, terdapat nilai:

$$
\begin{array}{ll}
\alpha & =6,445 \\
\beta 1 & =-4,737 \\
\beta 2 & =12,545 \\
\beta 3 & =28,118
\end{array}
$$

maka diperoleh rumus persamaan regresi berganda sebagai berikut:

$\mathrm{Y}=6,445-4,737 \mathrm{X} 1+12,545 \mathrm{X} 2+28,118 \mathrm{X} 3+\mathrm{e}$

Dari persamaan regresi diatas, dapat di uraikan sebagai berikut:

1. Konstanta $(\alpha)$ 


\section{JURNAL AKUNTANSI, Vol. 7, No. 2, November (2018)}

Besarnya nilai konstanta adalah 6,445 menunjukkan bahwa jika variabel independen yang terdiri dari Current Ratio, Profit Margin dan ROA nilainya tetap, maka nilai laba sebesar 6,445.

2. Koefisien Regresi Current Ratio

Besarnya nilai $\beta 1$ adalah $(-4,737)$ artinya jika Current Ratio meningkat sebesar 1 bagian maka akan menurunkan laba sebesar 4,737 bagian, namun tidak signifikan. .

3. Koefisien Regresi Profit Margin

34567890-

JBesarnya nilai B2 adalah 12,545 menunjukkan jika Profit Margin meningkat sebesar 1 bagian maka akan meningkatkan laba sebesar 12,545 bagian, namun tidak signifikan.

4. Koefisien Regresi Return On Assets Besarnya nilai B3 adalah 28,118 menunjukkan jika Return On Assets meningkat sebesar 1 bagian maka akan meningkatkan laba sebesar 28,118 bagian.

\section{PEMBAHASAN}

Berdasarkan uji t yang dilakukan, variabel current ratio tidak berpengaruh signifikan terhadap laba. Hal ini dapat dilihat dari hasil uji t1 hitung adalah 1,653 yang lebih kecil dari t tabel yaitu 1,753. Penelitian sebelumnya dilakukan oleh Ima Indriyani (2015) yaitu,variabel current ratio secara parsial tidak signifikan terhadap pertumbuhan laba pada perusahaan pertambangan yang terdaftar di BEI.

Uji t yang dilakukan pada variabel profit margin juga tidak berpengaruh terhadap laba. Berdasarkan hasil uji t2 hitung adalah 1,144 lebih kecil dari t tabel yaitu 1,753. Pada variabel Return on Asset hasil uji t3 hitung adalah 1,885 lebih besar dari t tabel yaitu 1,753 yang berarti ROA berpengaruh terhadap Laba dengan tingkat signifikansi 0,86 atau > 0,05 yang berarti tidak signifikan, namun berpengaruh signifikan pada level signifikansi $10 \%$.

Penelitian yang sama dilakukan oleh Azeria Ra Bionda dan Nera Marinda Mahdar (2017) yaitu Secara parsial Net Profit Margin (NPM) tidak berpengaruh positif dan signifikan terhadap Pertumbuhan Laba perusahaan dengan nilai signifikansi variabel bebas 0.186 yang lebih besar dari $\alpha 0.05$. Return on Asset(ROA), dan Return on Equity (ROE) berpengaruh positif dan signifikan terhadap Pertumbuhan Laba perusahaan dengan nilai signifikansi variabel bebas 0.05

Dari hasil uji anova atau $\mathrm{F}$ test menunjukkan bahwa $\mathrm{F}$ hitung adalah 8,566 $>$ dari $\mathrm{F}$ tabel $=3,06$ dengan tingkat signifikansi 0,003 . Karena 0,003 lebih kecil dari 0,05 maka pengaruh antara variabel independen terhadap dependen dinyatakan signifikan. Oleh karena itu, untuk tahun periode 2013-2016 keseluruhan hipotesis menyatakan bahwa variabel independen disini adalah Current Ratio, Profit Margin dan Return On Assets memiliki pengaruh yang signifikan terhadap Laba Perusahaan. Hasil penelitian ini mendukung penelitian sebelumnya oleh Wahyu Endah Dewanti (2016) bahwa Current Ratio, Debt to Equity Ratio, Return On Asset, Return On Equity, dan Net Profit Margin secara simultan berpengaruh signifikan terhadap Perubahan Laba

\section{PENUTUP}

Penelitian ini bertujuan untuk menguji pengaruh rasio likuiditas dan profitabilitas terhadap laba perusahaan dengan menggunakan Current Ratio (CR), Profit Margin (PM) dan Return on Assets (ROA). Berdasarkan hasil pengujian hipotesis, Current Ratio (CR) dan Profit Margin (PM) tidak berpengaruh signifikan terhadap laba perusahaan, hanya Return on Assets (ROA) yang berpengaruh signifikan terhadap laba perusahaan. Hasil ini menunjukkan bahwa factor penentu laba perusahaan pada PT. Dharma Satya Nusantara adalah Return on Assets (ROA).

Adapun saran berdasarkan hasil penelitian ini, PT Dharma Satya Nusantara sebaiknya lebih meningkatkan aktiva lancar, salah satunya dengan penjualan saham atau penjualan obligasi agar dapat 


\section{JURNAL AKUNTANSI, Vol. 7, No. 2, November (2018)}

mengurangi kewajiban lancar. PT. Dharma Satya Nusantara memiliki rasio profitabilitas yang baik, untuk lebih meningkatkan laba di tahun berikutnya perusahaan harus mampu mengelola modal yang diinvestasikan dalam aktiva dan meningkatkan pendapatan bersih untuk memperoleh laba bersih yang maksimal. Misalnya: dengan cara meningkatkan volume penjualan dan memaksimalkan penggunaan seluruh aktiva yang dimiliki dalam ke giatan operasi, agar dapat mengahasilkan laba yang maksimal. Sehingga tingkat Laba bisa meningkat di tahun-tahun yang akan datang.

\section{REFERENSI}

Bionda, A. R., \& Mahdar, N. M. (2017). Pengaruh gross profit margin, net profit margin, return on asset, dan return on equity terhadap pertumbuhan laba pada perusahaan manufaktur di bursa efek indonesia. Kalbisocio Jurnal Bisnis dan Komunikasi, 4(1).

Dewanti, W.E, Pengaruh Current Ratio (CR), Debt to Equity Ratio (DER), Return On Asset (ROA), Return On Equity (ROE), dan Net Profit Margin (NPM0 Terhadap Perubahan Laba Pada Perusahaan Manufaktur Sektor Industri Barang

Ghozali, Imam, 2007, Teori Akuntansi, Edisi ketiga, ISBN.

Harahap, Sofyan Syafri, 2016, Analisis Kritis atas Laporan Keuangan, Cetakan ketiga belas, Jakarta, PT Rajagrafindo Persada

Hery, 2014, Akuntansi Dasar 1 dan 2, Kompas Gramedia, Cetakan Ketiga, Jakarta.

Hery, 2016, Analisis Laporan Keuangan Edisi Pertama, Jakarta : PT Grasindo.

Indriyani, I. (2015). Pengaruh Rasio Keuangan Terhadap Pertumbuhan Laba Pada Perusahaan

Pertambangan Yang Terdaftar Di Bursa Efek Indonesia. Jurnal Manajemen dan Bisnis Sriwijaya, 13(3), 343-358.

Kasmir. 2011. Analisis Laporan Keuangan. Cetakan keempat. Jakarta: Rajawali Pers.

Kasmir, 2012, Analisis Laporan Keuangan, Cetakan kesembilan, Depok, PT Rajagrafindo Persada. Munawir, 2010, Analisa Laporan Keuangan, Yogyakarta : Liberty.

Prasetyo, Nurdin (2010) Pengaruh Rasio Keuangan Terhadap Laba Pada Perusahaan Manufaktur Yang

Terdaftar Di BEI. Undergraduate thesis, Universitas Diponegoro

Riana D, Diyani LA. 2016. Pengaruh Rasio Keuangan dalam Memprediksi Perubahan Laba pada Industri

Farmasi (Studi Kasus pada BEI Tahun 2011-2014). Jurnal Online Insan Akuntan.1(1):16-42

Suwardjono, 2016, Teori Akuntansi, Edisi Ketiga, Cetakan Kesembilan, Yogyakarta, BPFE.

Wati, L.N. 2017. Metodologi Penelitian Terapan Bisnis: Aplikasi SPSS, EVIEWS, SmartPLS, dan AMOS. Bandung: Mujahid Press. 